\title{
HIV virological non-suppression and its associated factors amongst children on antiretroviral therapy at a major paediatric treatment centre in Southern Ghana: a cross-sectional study
}

Adwoa K. A. Afrane ( $\nabla$ dadwoa@yahoo.com )

Department of Child Health, Korle Bu Teaching Hospital, Accra

Bamenla Q. Goka

Department of Child Health, University of Ghana Medical School, Accra

\section{Lorna Renner}

Department of Child Health, University of Ghana Medical School, Accra

\section{Alfred Edwin Yawson}

Department of Community Health, University of Ghana Medical School, Accra

\section{Yakubu Alhassan}

Department of Health Policy Planning and Management, School of Public Health, University of Ghana, Accra

\section{Seth N. Owiafe}

Department of Child Health, Korle Bu Teaching Hospital, Accra

\section{Seth Agyeman}

Department of Immunology, Korle Bu Teaching Hospital, Accra

\section{Kwamena W.C Sagoe}

Department of Medical Microbiology, School of Medicine and Dentistry, University of Ghana, Legon

\section{Awewura Kwara}

Division of Infectious diseases and Global Medicine, Unitersity of Florida Gainseville, FL

\section{Research Article}

Keywords: Antiretroviral therapy, Paediatric HIV, viral load, virological non-suppression

Posted Date: May 7th, 2021

DOl: https://doi.org/10.21203/rs.3.rs-448212/v1

License: @ (i) This work is licensed under a Creative Commons Attribution 4.0 International License. Read Full License

Version of Record: A version of this preprint was published at BMC Infectious Diseases on August 2nd, 2021. See the published version at https://doi.org/10.1186/s12879-021-06459-z. 


\section{Abstract \\ Background}

Children with human immunodeficiency virus (HIV) infection require lifelong effective Antiretroviral Therapy (ART). The aim of ART in HIV-infected persons is sustained viral suppression. There is limited information on virological non-suppression or failure and its associated factors in children in resource limited countries, particularly Ghana.

\section{Methods}

A cross-sectional study of 250 children aged 8 months to 15 years who had been on ART for at least 6 months attending the Paediatric HIV clinic at Korle Bu Teaching hospital in Ghana was performed. Socio-demographic, clinical, laboratory and ART Adherence related data were collected using questionnaires as well as medical records. Blood samples were obtained for viral load and CD $4^{+}$count determination. Viral load levels $>1000$ copies/ml on ART was considered virological non-suppression. Logistic regression was used to identify factors associated with virological non-suppression.

\section{Results}

The mean $( \pm S D)$ age of the study participants was $11.4 \pm 2.4$ years and the proportion of males was $53.2 \%$. Of the 250 study participants, 96 (38.4\%) had virological non-suppression. After adjustment for significant variables, the factors associated with non-suppressed viral load were female gender (AOR 2.51 [95\% Cl 1.04-6.07], $p=0.041$ ), having a previous history of treatment of tuberculosis (AOR 4.95 [95\% Cl 1.58-15.5], $p=0.006$ ), severe CD4 immune suppression status (CD4\% < 15\% / CD4+ count $<200$ cells $/ \mathrm{mm}^{3}$ ) at study recruitment (AOR 24.93 [95\% Cl 4.92-126.31], $p<0.001)$ and being on a Nevirapine based regimen (AOR 7.93 [95\% CI 1.58-1.15], $p=0.005)$.

\section{Conclusion}

The prevelance of virological non-suppression was high. Virological non-suppression was associated with a previous history of TB treatment, female gender, severe CD4 immune suppression status (CD4\% $<15 \% /$ CD $4^{+}$ count $<200$ cells $/ \mathrm{mm}^{3}$ ), at study recruitment and being on a Nevirapine based regimen. Early initiation of ART and phasing out Nevirapine based regimen might improve viral load suppression in children. In addition, children with a history of TB may need focused measures to maximize virological suppression.

\section{Background}

Human immunodeficiency virus (HIV) infection continues to be one of the most important infectious diseases worldwide. ${ }^{1,2}$ Antiretroviral therapy (ART) is an important component of the overall management plan for HIV/AIDS. The primary goal of ART is to suppress viral replication, which ultimately results in restoration of the immune system, reduction of the onward transmission of the HIV virus and a general improvement in the quality of life of people infected with HIV. ${ }^{3,4}$ In resource-limited settings, HIV viral load (HIV VL) monitoring is recommended by the WHO (World Health Organization) as a gold standard for monitoring treatment effectiveness 
in $2013,{ }^{5}$ and Ghana adopted these guidelines in 2016. According to Ghana's National Aids Control Program (NACP) guidelines, viral load testing is recommended 6 months after initiating ART and therafter annually for people who have achieved virological suppression. ${ }^{6}$ However people with HIV VL levels > 1000 copies/ml undergo intensified adherence support after which the viral load is repeated three months later in order to differentiate poor adherence from treatment failure. ${ }^{6}$

Virological non-suppression could be due to poor adherence to ART, resistance to ART (transmitted or acquired) or pharmacokinetic issues (poor absorption, under-dosing and drug interactions). 7,8 Adherence-related factors are most often caused by the patient. 7,8 ART regimen-related factors could result in the development of resistance. ${ }^{9,10}$

A wide range of factors are associated with virological non-suppression and these include socio-demographic factors such as younger age (less than three years), ${ }^{11}$ male gender, ${ }^{12,13}$ WHO advanced HIV stage, ${ }^{14,15}$ coinfection with tuberculosis (TB), ${ }^{16,17}$ nevirapine (NVP) based therapy, ${ }^{18,19}$ and poor adherence to treatment. ${ }^{20,21} \mathrm{~A}$ principle cause for virological non-suppression is non-adherence. ${ }^{21,22}$ The paediatric population are more likely to have challenges with adherence to $\mathrm{ART}^{23,24}$ because drug formulations for paediatric patients are often less tolerable, and require dose adjustment according to the weight as the child grows. ${ }^{2324}$ There are also specific challenges with the social context, such as a lack of consistent caregiver in younger children and disclosure issues, which pose a challenge to consistent adherence. ${ }^{23,24}$ These peculiar issues to children and adolescents can result in virological non-suppression, without necessarily leading to the development of drug resistance. ${ }^{8}$

High rates of virological non-supression suggests a higher risk of developing resistance and is common in children in Low-and middle-income countries. (LMICs) ${ }^{8}$, and this has implications for the spread of resistant HIV variants. Identifying patients with virological non-suppression is thus important for prompt detection of treatment failures and in identifying the characteristics of the population that might benefit from interventions such as intensified adherence counseling and increased frequency of follow up. ${ }^{31}$ This would in turn prevent the development of drug resistance in the population at risk. The aim of this study was therefore to determine the prevalence of virological non-suppression and its associated factors among children living with HIV (CLWH) attending a Paediatric HIV clinic at Teaching Hospital in Ghana. This knowledge would help to target interventions for improving virological suppression that will ultimately lead to improvement in clinical care.

\section{Methods}

\section{Study design and setting}

This study used a cross-sectional design to recruit paediatric HIV positive patients attending the outpatient clinic from October 2017 to July 2018 at the Korle Bu Teaching Hospital (KBTH), Accra, Ghana. KBTH has 2500 beds and is currently the largest hospital in West Africa and the third largest on the African continent. ${ }^{25}$ The hospital is the main tertiary referral centre in Accra and serves the majority of the southern half of Ghana. The Paediatric HIV clinic at KBTH has been providing comprehensive HIV/AIDS care and management services since 2004. Patients are referred from primary and secondary health facilities as well as from other departments within the hospital. An average of 40 patients are seen per clinic day. The National AIDS Control Program (NACP) provides ART medication free of charge. HIV VL and CD $4^{+}$counts are also paid for by the program. The clinic uses national 
treatment guidelines that are in line with current WHO recommendations for ART in Ghana. ${ }^{26}$ Treatment is initiated for all patients irrespective of the $C D 4^{+}$count. ART available and in use in various combinations at the clinic at the time of the study were zidovudine (AZT), lamivudine (3TC), abacvir (ABC), efavirenz (EFV), nevirapine (NVP), tenofovir (TDF), and ritonavir boosted Lopinavir (LPV/r).

\section{Study participants}

Study participants were Children living with HIV (CLHV) aged between 8 months and 15 years and who had been on ART for at least 6 months for whom caregivers/study participants had given informed written consent to participate in the study were enrolled. Children who had been transferred from referral points and did not have their previous notes available and children with HIV-2 mono infection were excluded from the study. There are currently no Food and Drug FDA-approved assays for quantification of HIV-2 RNA ${ }^{71}$ and hence the exclusion of children with HIV-2 mono infection. Voluntary informed consent was obtained from parents and guardians of study participants and assent from children aged 10-15years. Before seeking informed consent/assent, study participants were screened to determine whether they were eligble or not. A questionnaire was administered to study participants and caregivers. Information was also collected retrospectively from their medical records.

\section{Sample size determination}

The Cochran's sample size formula ${ }^{27}$ was used to calculate the sample size to determine the prevalence of nonsuppressed viremia. A minimum sample size of 250 study participants was determined using confidence level of $95 \%$ and an error margin of $5 \%$. Consecutive cases of HIV children who met the eligibility criteria were enrolled into the study until the sample size was reached.

\section{Data Collection}

Participants had their drug doses checked for appropriateness of their current drug regimen. The dosage, (frequency and dose/kg or $\mathrm{m}^{2}$ ) was cross checked with the recommended dosage and appropriateness was documented as 'yes' or 'no.' ART Adherence was assessed by a pharmacist on the day of recruitment using the pill count.

Pill count (the number of pills taken) was calculated based on the number of unused pills that the care giver brought back when refilling their ART medication on the day of study recruitment. ${ }^{155}$ Total refill was the expected number of pills to have been taken since the last visit.

Pill count was callulated as: see equation in the supplementary files.

\section{Laboratory analysis}

Laboratory investigations done on the day of recuitment were $\mathrm{CD} 4^{+}$count and HIV VL. CD $4^{+}$absolute cell count and cell percentage were quantified by a dual-platform flow cytometry technology using a FACS Count system (Becton-Dickinson, Franklin Lakes, NJ, USA) according to manufacturer's instructions at the Fevers Unit Laboratory of KBTH. The HIV RNA VL testing was performed at the Central Laboratory of KBTH using the COBAS ${ }^{\circledR}$ AMPLICOR Monitor test (Roche Diagnostic Systems, Branchburg, NJ, USA), with a a lower limit of detection of 20 copies/ml. The laboratory at the Fevers unit and the Central Lab KBTH are certified by the South African Public 
Health Reference Laboratory and participates in an external quality assurance testing programme by the South African Public Health Reference Laboratory.

\section{Operational definitions}

In accordance with WHO guidelines, study participants were categorized as having virological non-suppression if the HIV VL level was > 1000 copies/ml on the day of recruitment, after at least 6 months of using ART. Drug Adherence was determined by caregivers report and categorized according to WHO guidelines as follows: Good $\geq$ 95\%; Fair: 85-94\%: Poor < 85\%. ${ }^{28}$

\section{Statistical analysis}

The dependent variable was virological non-suppression (VL > 1000 copies $/ \mathrm{ml}$ ). The independent variables were the sociodemographic factors, clinical factors and ART Adherence factors. Pearson's chi-square test of association was used to determine strength of association between the independent categorical variables and the outcome variable (virological non-suppression). The logistic regression model was used in determining the factors influencing HIV VL suppression amongstudy participants with statistical significance set at $p<0.05$. The crude odds ratio (OR) and adjusted odds ratio (AOR) were determined and OR and their respective $95 \%$ confidence intervals were calculated.

\section{Ethical considerations}

Ethical appproval (KBTH-IRB/ 00060/2017) was obtained from the Institutional Review Board of Korle Bu Teaching Hospital, Accra, Ghana. Informed consent was obtained from parents or legal guardians for each minor participant prior to enrolment to participate in the study.

\section{Results}

\section{Baseline characteristics}

The baseline characterteistics of all 250 patients are shown in Table 1. The mean duration on ART was 64 months \pm 3.0 months. More than half $133(53.2 \%)$ of the study participants were males. Majority of the study participants $148(59.2 \%)$ were within the age range of 10 to 15 years. Overall, the mothers of $157(62.8 \%)$ participants were HIV positive while $93(37.2 \%)$ of mothers had unknown HIV status. The fathers of $62(24.8 \%)$ study participants were HIV positive whilst 105 (42.0\%) were HIV negative and 83 (33.2\%) had unknown HIV status. Primary caregivers who were mothers were 115 (46.0\%), fathers were 25 (10.0\%) and 110 (44\%) were guardians (grandmother, grandfather, aunt, uncle, foster caregiver). The unknown status included parents who were dead. The educational and occupation of parents is described in Table 1.

\section{Clinical and laboratory details of study participants}

A significant number of study participants 97 (38.8\%) were in WHO clinical stage one at initiation of ART. Of all participants, $71(28.4 \%)$ had a history of previous TB treatment.

\section{Baseline $\mathrm{CD} 4^{+}$count and VL of study participants}


Overall, of the 225 study participants that had records for their Baseline CD4 ${ }^{+}$counts, 35 (15.6\%) had severe CD4 immune suppression status (CD4\% <15\% / CD $4^{+}$count $<200$ cells $/ \mathrm{mm}^{3}$ ), $25(11.1 \%)$ had advanced CD4 immune suppression status (CD4 \%: 15-19\% / CD4 count: 200-349 cells/mm³), 18 (8\%) had mild CD4 immune status (CD4 \%: $20-25 \% /$ CD $^{+}$count: $350-499$ cells $/ \mathrm{mm}^{3}$ ) with the majority of study participants $147(65.3 \%)$ having normal $\mathrm{CD}^{+}$status (CD4 \% >25\% / CD4 count: > 500 cells $\left./ \mathrm{mm}\right){ }^{3}$ Out of the 250 study participants, only 74 (30\%) had baseline $\mathrm{VL}$ documented. Of the 74 study participants that had records of baseline $\mathrm{VL}$, a significant number 30 (40.5\%), had baseline VL < 10, 000 copies/ml, 22 (29.7\%) had VL levels between (10, 000 and 99,999), 12 (16.2\%) have VL levels between (100,000 and 4999,999 and 10 (13.5\%) have viral load levels $\geq 5000,000$.

\section{CD4 ${ }^{+}$count at study recruitment}

The $\mathrm{CD} 4^{+}$results for 20 of the study participants were not available because of technical issues that occurred with their blood samples at the laboratory. Of the 230 that had CD $4^{+}$results on the day of study recruitment, 10 (4.3\%) were children less than 5 years and 220 (95.7\%) were children between 5 and 15 years of age. For the overall CD $4^{+}$ immune suppression status, 24 (10.4\%) had severe immune suppression status, (CD $4 \%<15 \%$ / CD 4 count < 200 cells $\left./ \mathrm{mm}^{3}\right), 18$ (7.8\%) had advanced immune suppression status (CD4\%: 15-19\% / CD4+ count: 200-349 cells $/ \mathrm{mm}^{3}$ ), 23 (10\%) had mild immune suppression status (CD4 \%: 20-25\% / CD4 count: 350-499 cells/mm³) and 165 (71.7\%) had normal CD4 ${ }^{+}$immune status (CD4 \%: >25\% / CD4 ${ }^{+}$count: > 500 cells/mm). ${ }^{3}$

\section{Proportion of patients with virological non-suppression}

At study enrolment, 96 (38.4\%) of the 250 study participants had virological non-suppression (VL > 1000 copies/mls). Study participants with low-level viraemia (VL level 20-1000 copies/ml) were 58 (23.2\%) and those with VL levels < 20 copies/ml were 96 (38.4\%). For virological non-suppression within the various age groups, 14 $(46.7 \%)$ were within the age group (< 5 years), 28 (38.9\%) were within the age group (5-9 years) and 54 (36.5\%) were within the age group (10 -15 years).

\section{Factors associated with virological non-suppression}

Bivariate analysis of factors associated with virological non-suppression are shown in Table 1. Females were more likely to have virological non-suppression in comparison to males $(54.2 \%$ vs $32.2 \%, p=0.035)$. The overall $\mathrm{CD} 4^{+}$immune suppression status of the subject at study recruitment showed a significant association with the subjects VL. (Fischer's exact $(\Phi, p<0.001)$. The adherence rate of subject measured by pill count percentage showed a significant association with the subjects $V L\left(\chi^{2}=7.99, p=0.018\right)$.

There were no significant differences for the following variables: age of subject, primary caregiver's relationship to subject, educational status of father, educational status of mother, occupational status of father, occupational status of mother, history of previous TB treatment, WHO stage at initiation of ART, baseline VL and baseline CD4 ${ }^{+}$ count values (overall), duration on ART, current ART regimen and person responsible for child's medication (Table $1)$. 


\section{Factors associated with virological non-suppression in multivariate analysis}

In multivariate analysis of patients, females were 2.5 times more likely to have virological non-suppression when compared with male study participants (AOR 2.51 [95\% Cl 1.04-6.07], p =0.041). Additionally, study participants with severe $\mathrm{CD}^{+}{ }^{+}$immune suppression status at study recruitment were 9 times more likely to have virological non-suppression when compared to children with normal $C D 4^{+} /$no immune suppression in multivariate analysis (AOR 24.93 [95\% Cl 4.92-126.31], p < 0.001). Participants with a prior history of TB treatment were 4.95 times more likely to have virological non-suppression as compared to participants without a prior history of TB treatment (AOR 4.95 [95\% Cl 1.58-15.5], p < 0.006). Participants with a NVP based regimen was 7.93 times more likely to be associated with virological non-suppression (AOR 7.93 [95\% CI 1.58-15.5], $p=0.005$ ). Multivariate analysis of adherence pill count did not yield any significant results (Table 2).

Table 2: Univariate and multivariate analysis of factors associated with virological non suppression in CLWH on ART for a at least 6 months $(\mathrm{N}=250)$ 


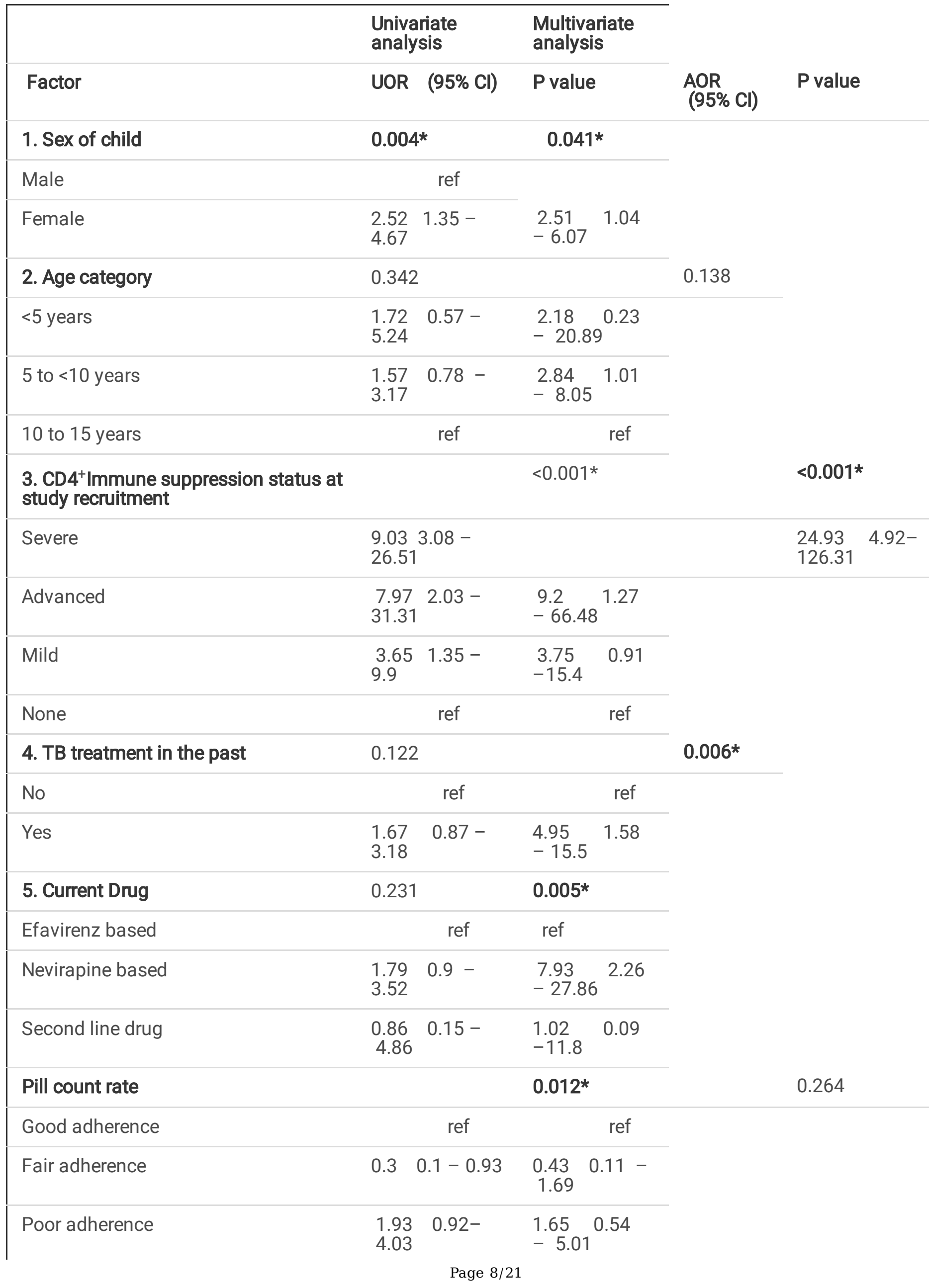




\section{*: $p<0.05$.}

\section{Discussion}

In this cross-sectional study, a relatively large proportion of the $250 \mathrm{CLHV}(38 \%)$ had virological non-suppression after being on ART for a mean period of $64 \pm 3.0$ months. Female gender, having a previous history for TB treatment, severe $\mathrm{CD} 4^{+}$immunodeficiency status at study recruitment and a NVP-based regimen were associated with virological non-suppression. Some factors identified in other studies such as adherence to ART, clinical stages 3 and 4, parent's educational level and their employment status were not significant in this current study.

As antiretroviral access continues to expand in resource-limited countries like Ghana, monitoring response to ART by the use of VL measurements is critical in determining the effectiveness of ART in the population. ${ }^{29,173}$ The SubSaharan African region's prevalence for virological non-suppression (>1000 copies $/ \mathrm{ml}$ ) in children who have been on ART for at least 6 months ranges from $13 \%$ to $44 \% .8,30,31$ A virological non-suppression rate of $38 \%$ found in this study increases the risk for the emergence of ART resistance and subsequently failure of the ART regimen, necessitating a switch to second, or later third line treatment. ${ }^{8}$ This ultimately would result in an increase in morbidity and mortality of the CLHV and cause the spread of resistant viruses. ${ }^{8}$ Given these consequences, VL monitoring per national guidelines should be routinely done in all children on ART and those identified as being virologically non-suppressed, should have adherence counselling and then a repeat viral load level to confirm if they have virological failiure. Once virological failure has been confirmed then the various drug switch should occur according to Standard Treatment Guidelines outlined by NACP. ${ }^{6}$

The rate of non-suppression observed in this study could be due to a number of reasons. Firstly, VL monitoring has been a programmatic challenge at the Paediatric HIV clinic in the study setting, characterized by frequent interruptions in the availbility of resources required by the laboratory, resulting in erratic provision of services. Without close monitoring of VL levels, the patients are at risk of unrecognized virological failure as continuing a failing regimen is associated with accumulation of HIVDR variants. ${ }^{168}$ Adequate funding and improved logisitics management to ensure uninterrupted VL testing in the laboratory would boost the implementation of the VL monitoring protocol that exisits in the clinic.

We observed a relatively high proportion of patients with virological non-suppression (38\%). This translates to a virological suppression rate of $62 \%$ and is similar to the estimate made by Ghana in respect of its achievement of the third 90 of the UNAIDS 90-90-90 targets. This shows that more effort should be made as a country in achieveing the current 95-95-95 targets which has been proposed by UNAIDS with the purporse of ending AIDS by $2030 .^{32}$

The prevalence of children with detectable viral loads above 20 copies/ml but less than 1000 copies/ml (low level viraemia (LLV)) in this study was $23 \%$. This group of patients are denoted as 'non-failures' and WHO does not make any provision for the management of LLV. These group of individuals will not receive any follow-up VL for at least six to 12 months and thus risk continuing on a failing regimen for considerable time. There is therfore the need to design algorithms for patients with LLV to have more frequent VL monitoring as literature has shown the emergence of high-level resistance in this group of individuals. ${ }^{33}$ 
We observed that females were 2.5 times more likely to have virological non- suppression as compared to males. This phenomenon was similar to the study by Muri et $a l_{,}^{34}$ in Tanzanian children, whereby females were also 2.5 more times likely to have virological non-suppression. On the contrary, some studies have reported that males had increased odds of virological non-suppression, ${ }^{13,35}$ whilst other studies however found no association between sex and virological non-suppression. ${ }^{36}$ The role of gender in virological suppression could be biologic according to authors such as Njom et al. ${ }^{37}$ The relationship of virological suppression and gender is therefore inconclusive and requires further studies.

A third of the study population had been previously treated for TB. Furthermore, having a history of previous TB treatment increased the odds of having virological non-suppression by as much as five times. These findings are in agreement with studies reported by Ahoua et $a l^{38}$ and by Rajin et $a l^{39}{ }^{39}$ On the other hand, it has been recently reported that children who had a history of TB co-infection had better virological outcomes. ${ }^{13}$ Reasons for this could be due to the close monitoring, frequent clinic visits and adherence support, adopted as part of TB treatment offered at the sample sites. The association of a previous history of TB and virological non-suppression in this current study could be due to the increased pill burden and drug-drug interactions between the medications that these patients are on. The significance of TB comorbidity on the occurrence of virological non-suppression buttresses the need for the prioritization of VL monitoring and adherence support in co-infected patients as well as patients who have a history of previous TB.

The odds of virological non-suppression was almost eight times more likely in study participants whose current drug regimen was NVP-based as compared to a study participant who had an EFV-based regimen. The findings of this study is consistent with current literature that shows that patients on NVP-based regimens experience more virological failure than patients on EFV-based regimens. ${ }^{18,19}$ The use of regimens containing NVP is associated with a low genetic barrier of drug resistance and a higher risk of baseline resistance in cases where NVP was used as prophylaxis in the babies for Prevention of Mother To Child Transmission (PMTCT). This current study however did not evaluate prior NVP exposure. Our findings support the current ART guidelines being used at the HIV clinic at KBTH which is to phase out NVP based regimens and replace with LPV/r or EFV regimens for children less than $20 \mathrm{~kg}$. Current guidelines recommend a Dolutegravir (DTG) based regimen as the preferred first-line for children weighing at least $20 \mathrm{~kg}$. Hopefully with the introduction of DTG and its scale up, the non suppression due to certain antiretroviral drugs such as NVP will be reduced.

We observed that study participants found to have severe CD $4^{+}$immune suppression status at the time of study recruitment were 25 times more likely to have virological non-suppression. These findings are in congruence with studies reported by Jobanputra et al, ${ }^{36}$ among children in Swaziland and by Izudi et al, ${ }^{40}$ among children in Northwestern Uganda where it was found that patients with low CD4 ${ }^{+}$count values at study recruitment were more likely to have virological non-suppression. This finding is expected and supports the knowledge that viral suppression leads to immune recovery and could reflect the fact that those study participants who were virologically suppressed had a chance to reconstitute their immune systems for their CD $4^{+}$counts to increase. ${ }^{41}$ This finding also supports early initiation of ART in children and according to the current ART guideline in Ghana, all children confirmed to have HIV diagnosis after birth are started on ART regardless of the CD4+ count.

There was no association between parent-educational level, employment status of parent and virological nonsuppression in this study. This is in agreement with a Danish HIV Cohort reported by Legarth et al ${ }^{42}$ which also showed no association between education level and virological non-suppression. This finding is however in 
contrast to a study reported by Mensah et $a^{A 3}$ in Ghana, in which a child with an unemployed caregiver was five times more likely to have virological non-suppression. There is substantial evidence on the socioeconomic inequalities in the treatment outcomes of chronic diseases like HIV. This current study could not confirm association between employment status and virological non-suppression. This observation could be due to the fact that for almost a third of study participants, the educational and employment status of parents was not known.

Studies on the relationship between self-reported adherence to ART and virological non- suppression have shown inconsistent results. ${ }^{20,44}$ In this study, adherence level measured by pill count was not associated with virological non-suppression. On the other hand in a clinical trial reported by Intasanet $\mathrm{al}^{45}$ in Cambodian children, nonadherence was associated with virological non-suppression. The measure of adherence used in the study by Intasanet $a l_{,}^{45}$ was however the 3 day self -report by caregiver. In a more recent research by Natukunda et al, ${ }^{31}$ in adolescents, reported in 2019 , more than $70 \%$ of adolescents who experienced virological non-suppression were sufficiently adherent as measured by pill count ( adherence $>95 \%$ ). On the other hand, there are also studies whereby poorly adherent patients maintained undetectable VL. 44,46

The strength of this current study is that it did not only determine the prevalence of virological non-suppression but explored factors associated with the phenomenon in children. In the absence of drug resistance testing information, close monitoring of VL levels, multidisciplinary support and prompt clinical judgment are key in ensuring children who have failed treatment are appropriately transitioned to second line therapy. Ultimately, 'an ounce of prevention is better than a pound of cure.'

Limitation: The reliance on self-reported data as a measure of adherence, which may be affected by recall and social desirability bias. Analysis of baseline VL and CD4 ${ }^{+}$count was not available for some of the subjects and hence analysis on baseline $\mathrm{VL}$ and $\mathrm{CD} 4^{+}$could not be done for those patients. This is because VL monitoring was started in April 2011 (as a national policy) and hence all children above eight years of age did not have the opportunity of having a baseline VL level done.

\section{Conclusion}

The high rate of virological non-suppresion is consistent with findings in other countries in Sub-Saharan setting and emphasizes the great challenge to successfully suppressing HIV in paediatric patients and reinforces the need for regular monitoring of viral load levels in children. Patients on ART with active TB and those with a history of previous TB should be prioritized for more regular VL monitoring (6 monthly) as the national guidelines advocate for yearly monitoring of viral load for patients whose viral load levels are suppressed. Further research should focus on determining resistance patterns in this study population.

\section{Declarations}

\section{Ethics approval and consent to participate}

Ethical approval (KBTH-IRB/ 00060/2017) was obtained from the Institutional Review Board of Korle Bu Teaching Hospital, Accra, Ghana. An informed consent was obtained from parents or legal guardians for each minor participant prior to enrolment to participate in the study. All procedures performed involving study participants 
were in accordance with the ethical standards of the institutional and/or national research committee and with the 1964 Helsinki declaration and its later amendments or comparable ethical standards.

\section{Consent for publication}

Not applicable.

\section{Availability of data and materials}

The data sets used and analysed during this study are available with the corresponding author on request.

\section{Competing interest}

All authors declare that there are no competing interests.

\section{Funding}

AKAA and AK received support from University of Florida-University of Ghana Training Program in Tuberculosis and HIV Research in Ghana funded by Fogarty International Center at the National Institutes of Health (grant number D43 TW010055) for training.

\section{Authors' contributions}

AKAA contributed to conception and study design, acquisition of data, analysis and interpretation of data and drafting of the manuscript. AK, BG, LR contributed to study design, interpretation of data and substantively revised it. SO contributed to acquisition of data. SA contributed to laboratory testing. YA contributed to analysis of data and interpretation of data. AEY contributed to analysis of data, interpretation of data and substantively revised it. KWCS contributed to conception and study design, interpretation of data and substantively revised it. All authors read and approved the final manuscript.

\section{Acknowledgments}

The following people have contributed in diverse ways to the study, Prof Margaret Lartey, Dr. Nyonuku Akosua Baddoo, Dr. Timothy Archampong, Dr. Emilia Udofia, Dr. Frank Owusu Sekyere, Dr. Bola Ozoya, Dr. Jocelyn Dame, Dr. Claire Keane, Dr. Abena Takyi, Mr. Isaac Boamah, Miss Christabel Siaw-Akugbey, Mr. Derrick Tetteh, Mrs. Obedia Seneake, Miss Sarah Brew and Mr. Shittu Dhikrullahi. I also acknowledge the UG-UF D43 training grant that supported me to take a course in research proposal development for this study.

\section{Abbreviations}

ABC - Abacavir

AIDS - $\quad$ Acquired Immunodeficiency Syndrome

AOR - $\quad$ Adjusted Odds Ratio

ART - $\quad$ Antiretroviral Therapy

CD4 - $\quad$ Cluster of differentiation 4 
CD4\% - $\quad$ CD4 percentage

CLHV Children Living with HIV

DTG - $\quad$ Dolutegravir

EFV Efavirenz

ELISA - Enzyme-linked immunosorbent assay

FDA Food and Drug Administration

HIV $\quad$ - $\quad$ Human Immunodeficiency Virus

HIV VL HIV viral load

KBTH - $\quad$ Korle Bu Teaching Hospital

LMIC - $\quad$ Low- and middle-income countries

LLV - $\quad$ Low level viraemia

$\mathrm{LPV} / \mathrm{r}$ - $\quad$ ritonavir boosted lopinavir

NACP - National AIDS Control Programme

NVP - $\quad$ Nevirapine

PCR - Polymerase Chain Reaction

PI - Protease Inhibitor

SPSS - $\quad$ Statistical Package for Social Sciences

TEN - Tenofovir

TB - Tuberculosis

VL - $\quad$ HIV-1 RNA Viral Load

U.O.R - $\quad$ Unadjusted Odds Ratio

27 WHO - $\quad$ World Health Organization

ZDV - Zidovudine

3TC - $\quad$ Lamivudine

References 
1 History of HIV and AIDS overview | Avert. https://www.avert.org/professionals/history-hiv-aids/overview (accessed 26 Dec2019).

2 HIV/AIDS Facts, Prevention, Signs, Symptoms \& Medications. eMedicineHealth. https://www.emedicinehealth.com/hivaids/article_em.htm (accessed 26 Dec2019).

3 Reddi A, Leeper SC, Grobler AC, Geddes R, France KH, Dorse GL et al. Preliminary outcomes of a paediatric highly active antiretroviral therapy cohort from KwaZulu-Natal, South Africa. BMC Pediatr 2007; 7: 13.

4 Aids $\mathrm{C}$ on P, Health S on IC. Increasing Antiretroviral Drug Access for Children With HIV Infection. Pediatrics 2007; 119: 838-845.

5 WHO | Consolidated guidelines on HIV prevention, diagnosis, treatment and care for key populations. WHO. http://www.who.int/hiv/pub/guidelines/keypopulations-2016/en/ (accessed 20 Sep2016).

6 National AIDS/STI Control Programme, Ghana Health Service. 2016 HIV Sentinel Survey Report. 2016.

7 talent maphosa. 6. hiv antiretroviral resistance. 14:27:59

UTC.https://www.slideshare.net/talentmaphosa1/6-hiv-antiretroviral-resistance (accessed 26 Dec2019).

8 Bulage L, Ssewanyana I, Nankabirwa V, Nsubuga F, Kihembo C, Pande G et al. Factors Associated with Virological Non-suppression among HIV-Positive Patients on Antiretroviral Therapy in Uganda, August 2014-July 2015. BMC Infect Dis 2017; 17. doi:10.1186/s12879-017-2428-3.

9 WHO | Global action plan for HIV drug resistance 2016-2021.

https://www.who.int/hiv/pub/drugresistance/hiv-drug-resistance-brief-2016/en/ (accessed 13 Feb2019).

10 Hamers RL, Wit TFR de, Holmes CB. HIV drug resistance in low-income and middle-income countries. Lancet HIV 2018; 5: e588-e596.

11 Bacha T, Tilahun B, Worku A. Predictors of treatment failure and time to detection and switching in HIVinfected Ethiopian children receiving first line anti-retroviral therapy. BMC Infect Dis 2012; 12: 197.

12 Janssens B, Raleigh B, Soeung S, Akao K, Te V, Gupta J et al. Effectiveness of highly active antiretroviral therapy in HIV-positive children: evaluation at 12 months in a routine program in Cambodia. Pediatrics 2007; 120: e1134-1140.

13 Kadima J, Patterson E, Mburu M, Blat C, Nyanduko M, Bukusi EA et al. Adoption of routine virologic testing and predictors of virologic failure among HIV-infected children on antiretroviral treatment in western Kenya. PLOS ONE 2018; 13: e0200242.

14 Rupérez M, Pou C, Maculuve S, Cedeño S, Luis L, Rodríguez J et al. Determinants of virological failure and antiretroviral drug resistance in Mozambique. J Antimicrob Chemother 2015; 70: 2639-2647.

15 Yassin S, Gebretekle GB. Magnitude and predictors of antiretroviral treatment failure among HIV-infected children in Fiche and Kuyu hospitals, Oromia region, Ethiopia: a retrospective cohort study. Pharmacol Res Perspect 2017; 5. doi:10.1002/prp2.296. 
16 Komati S, Shaw PA, Stubbs N, Mathibedi MJ, Malan L, Sangweni P et al. Tuberculosis Risk Factors and Mortality for HIV Infected Persons Receiving Antiretroviral Therapy in South Africa. AIDS Lond Engl 2010; 24: $1849-1855$.

17 Costenaro P, Penazzato M, Lundin R, Rossi G, Massavon W, Patel D et al. Predictors of Treatment Failure in HIV-Positive Children Receiving Combination Antiretroviral Therapy: Cohort Data From Mozambique and Uganda. J Pediatr Infect Dis Soc 2015; 4: 39-48.

18 Pillay P, Ford N, Shubber Z, Ferrand RA. Outcomes for Efavirenz versus Nevirapine-Containing Regimens for Treatment of HIV-1 Infection: A Systematic Review and Meta-Analysis. PLOS ONE 2013; 8. doi:10.1371/journal.pone.0068995.

19 Mgelea EM, Kisenge R, Aboud S. Detecting virological failure in HIV-infected Tanzanian children. SAMJ South Afr Med J 2014; 104: 696-699.

20 Nieuwkerk PT, Oort FJ. Self-reported adherence to antiretroviral therapy for HIV-1 infection and virologic treatment response: a meta-analysis. J Acquir Immune Defic Syndr 1999 2005; 38: 445-448.

21 Gross R, Bilker WB, Friedman HM, Strom BL. Effect of adherence to newly initiated antiretroviral therapy on plasma viral load. AIDS Lond Engl 2001; 15: 2109-2117.

22 Wood E, Hogg RS, Yip B, Moore D, Harrigan PR, Montaner JS. Impact of baseline viral load and adherence on survival of HIV-infected adults with baseline CD4 cell counts $\geq 200$ cells/ $\mu$ : AIDS 2006; 20: 1117-1123.

23 Marhefka SL, Koenig LJ, Allison S, Bachanas P, Bulterys M, Bettica L et al. Family experiences with pediatric antiretroviral therapy: responsibilities, barriers, and strategies for remembering medications. AIDS Patient Care STDs 2008; 22: 637-647.

24 Haberer JE, Kiwanuka J, Nansera D, Ragland K, Mellins C, Bangsberg DR. Multiple Measures Reveal Antiretroviral Adherence Successes and Challenges in HIV-Infected Ugandan Children. PLOS ONE 2012; 7: e36737.

25 About us - Brief History. http://kbth.gov.gh/brief-history/ (accessed 3 Jan2019).

26 Consolidated Guidelines on the Use of Antiretroviral Drugs for Treating and Preventing Hiv Infection: Recommendations for a Public Health Approach. 2016http://www.deslibris.ca/ID/10089566 (accessed 11 Apr2019).

27 Heinisch O. Cochran, W. G.: Sampling Techniques, 2. Aufl. John Wiley and Sons, New York, London 1963. Preis s. Biom Z1965; 7: 203-203.

28 WHO | Antiretroviral therapy of HIV infection in infants and children: towards universal access. WHO. http://www.who.int/hiv/pub/guidelines/art/en/ (accessed 23 May2017).

29 Tucker JD, Bien CH, Easterbrook PJ, Doherty MC, Penazzato M, Vitoria M et al. Optimal strategies for monitoring response to antiretroviral therapy in HIV-infected adults, adolescents, children and pregnant women: a systematic review. AIDS Lond Eng/2014; 28 Suppl 2: S151-160. 
30 Makadzange AT, Higgins-Biddle M, Chimukangara B, Birri R, Gordon M, Mahlanza T et al. Clinical, Virologic, Immunologic Outcomes and Emerging HIV Drug Resistance Patterns in Children and Adolescents in Public ART Care in Zimbabwe. PLOS ONE 2015; 10. doi:10.1371/journal.pone.0144057.

31 Natukunda J, Kirabira P, Ong KIC, Shibanuma A, Jimba M. Virologic failure in HIV-positive adolescents with perfect adherence in Uganda: a cross-sectional study. Trop Med Health 2019; 47. doi:10.1186/s41182-019-0135-z.

32 Ending AIDS: progress towards the 90-90-90 targets | UNAIDS.

http://www.unaids.org/en/resources/documents/2017/20170720_Global_AIDS_update_2017 (accessed 14 Feb2019).

33 NNRTI Resistance Notes - HIV Drug Resistance Database. https://hivdb.stanford.edu/drsummary/resistance-notes/NNRTI/ (accessed 8 Mar2019).

34 Muri L, Gamell A, Ntamatungiro AJ, Glass TR, Luwanda LB, Battegay M et al. Development of HIV drug resistance and therapeutic failure in children and adolescents in rural Tanzania: an emerging public health concern. AIDS Lond Eng/2017; 31: 61-70.

35 Kamya MR, Mayanja-Kizza H, Kambugu A, Bakeera-Kitaka S, Semitala F, Mwebaze-Songa P et al. Predictors of Long-Term Viral Failure Among Ugandan Children and Adults Treated With Antiretroviral Therapy: JAIDS J Acquir Immune Defic Syndr 2007; 46: 187-193.

36 Jobanputra K, Parker LA, Azih C, Okello V, Maphalala G, Kershberger B et al. Factors Associated with Virological Failure and Suppression after Enhanced Adherence Counselling, in Children, Adolescents and Adults on Antiretroviral Therapy for HIV in Swaziland. PLOS ONE 2015; 10: e0116144.

37 Njom Nlend AE, Motaze AN, Ndiang ST, Fokam J. Predictors of Virologic Failure on First-line Antiretroviral Therapy Among Children in a Referral Pediatric Center in Cameroon. Pediatr Infect Dis J 2017; 36: 1067.

38 Ahoua L, Guenther G, Pinoges L, Anguzu P, Chaix M-L, Le Tiec C et al. Risk factors for virological failure and subtherapeutic antiretroviral drug concentrations in HIV-positive adults treated in rural northwestern Uganda. BMC Infect Dis 2009; 9: 81.

39 Rajian M, Gill PS, Chaudhary U. Effect of Tuberculosis Co infection on Virological Failure in HIV Patients on First Line of Highly Active Antiretroviral Therapy. Int J Curr Microbiol App/ Sci 2017; 6: 78-81.

40 Izudi J, Alioni S, Kerukadho E, Ndungutse D. Virological failure reduced with HIV-serostatus disclosure, extra baseline weight and rising CD4 cells among HIV-positive adults in Northwestern Uganda. BMC Infect Dis $2016 ; 16$. doi:10.1186/s12879-016-1952-x.

41 Bayu B, Tariku A, Bulti AB, Habitu YA, Derso T, Teshome DF. Determinants of virological failure among patients on highly active antiretroviral therapy in University of Gondar Referral Hospital, Northwest Ethiopia: a case\&ndash;control study. HIVAIDS - Res. Palliat. Care. 2017. doi:10.2147/HIV.S139516.

42 Legarth R, Omland LH, Kronborg G, Larsen CS, Pedersen C, Gerstoft J et al. Educational attainment and risk of HIV infection, response to antiretroviral treatment, and mortality in HIV-infected patients. AIDS Lond Eng/2014; 28: 387-396. 
43 Mensah E. Predictors of Virological failure among children infected with HIV-1 on Haart at KATH. 2017.http://ir.knust.edu.gh:8080/handle/123456789/10001 (accessed 4 Feb2019).

44 Measurement Issues in Using Pharmacy Records to Calculate Adherence to Antiretroviral Drugs: HIV Clinical Trials: Vol 14, No 2. https://www.tandfonline.com/doi/abs/10.1310/hct1402-68 (accessed 2 Feb2019).

45 Intasan J, Bunupuradah T, Vonthanak S, Kosalaraksa P, Hansudewechakul R, Kanjanavanit S et al. Comparison of Adherence Monitoring Tools and Correlation to Virologic Failure in a Pediatric HIV Clinical Trial. AIDS Patient Care STDs 2014; 28: 296.

46 Use of a prescription-based measure of antiretroviral therapy adherence to predict viral rebound in HIVinfected individuals with viral suppression - Cambiano - 2010 - HIV Medicine - Wiley Online Library. https://onlinelibrary.wiley.com/doi/full/10.1111/j.1468-1293.2009.00771.x (accessed 2 Feb2019).

\section{Table 1}

Table 1: Baseline characteristics of patients according to virological suppression status 


\begin{tabular}{|c|c|c|c|c|c|}
\hline & $\begin{array}{l}\text { VL at study } \\
\text { (copies } / \mathrm{ml} \text { ) }\end{array}$ & recruitment & & & \\
\hline & $\begin{array}{r}\text { Suppressed } \\
(\leq 1000)\end{array}$ & $\begin{array}{c}\text { Non } \\
\text { suppressed } \\
(>1000)\end{array}$ & & & \\
\hline Characteristics & n (\%) & $\mathbf{N}(\%)$ & Total & $x^{2}$ & $P$ value \\
\hline Age category & & & & 1.10 & 0.576 \\
\hline$<5$ years & $16(53.3)$ & $14(46.7)$ & $\begin{array}{c}30 \\
(100.0)\end{array}$ & & \\
\hline 5 to $<10$ years & 44 (61.1) & 28 (38.9) & $\begin{array}{c}72 \\
(100.0)\end{array}$ & & \\
\hline 10 to 15 years & $94(63.5)$ & $54(36.5)$ & $\begin{array}{c}148 \\
(100.0)\end{array}$ & & \\
\hline Sex of child & & & & 4.43 & $0.035^{*}$ \\
\hline Female & $64(54.7)$ & $53(45.3)$ & $\begin{array}{c}117 \\
(100.0)\end{array}$ & & \\
\hline Male & $90(67.7)$ & $43(32.3)$ & $\begin{array}{c}133 \\
(100.0)\end{array}$ & & \\
\hline
\end{tabular}

\section{Primary}

caregiver

relationship to

subject

\begin{tabular}{|c|c|c|c|c|c|}
\hline Mother & $45(39.1)$ & $70(60.9)$ & $\begin{array}{c}115 \\
(100.0) \\
25\end{array}$ & 2.15 & 0.499 \\
\hline Father & $12(48.0)$ & $13(52.0)$ & $(100.0)$ & & \\
\hline Guardian & $50(45.5)$ & $60(54.5)$ & $\begin{array}{c}110 \\
(100.0)\end{array}$ & & \\
\hline $\begin{array}{l}\text { Educational status } \\
\text { father }\end{array}$ & & & & 4.16 & 0.527 \\
\hline None & $11(57.9)$ & $8(42.1)$ & $\begin{array}{l}19 \\
(100.0)\end{array}$ & & \\
\hline $\begin{array}{l}\text { Basic } \\
\text { (Primary/JHS/Middle) }\end{array}$ & $36(40.0)$ & $29(60.0)$ & $\begin{array}{l}65 \\
(100.0)\end{array}$ & & \\
\hline Secondary & 53 (64.6) & 29 (35.4) & $\begin{array}{l}82 \\
(100.0)\end{array}$ & & \\
\hline Tertiary & $19(73.1)$ & $7(26.9)$ & $\begin{array}{l}26 \\
(100.0)\end{array}$ & & \\
\hline $\begin{array}{l}\text { Educational status } \\
\text { mother }\end{array}$ & & & & 1.27 & 0.938 \\
\hline None & $15(55.6)$ & $12(44.4)$ & $\begin{array}{l}27 \\
(100.0)\end{array}$ & & \\
\hline
\end{tabular}




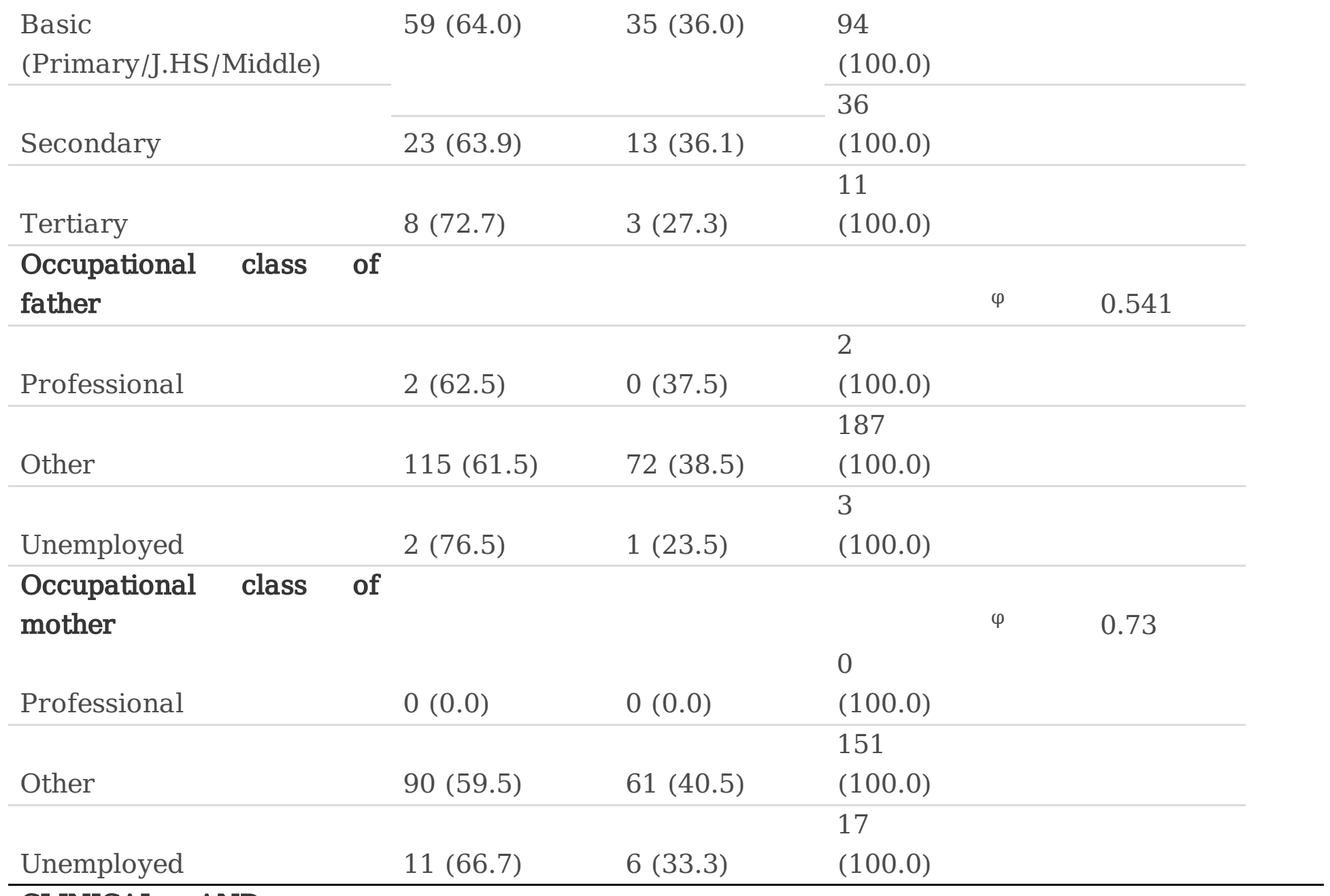

\section{CLINICAL AND}

\section{LAB VARIABLES}

TB treatment in

\begin{tabular}{|c|c|c|c|c|c|}
\hline the past & & & & 2.74 & 0.098 \\
\hline no & $116(64.8)$ & $63(35.2)$ & 179 (100.0) & & \\
\hline yes & $38(53.5)$ & $33(46.5)$ & $71(100.0)$ & & \\
\hline \multicolumn{6}{|l|}{ WHO stage at } \\
\hline ART initiation & & & & 1.82 & 0.611 \\
\hline Stage 1 & $64(66.0)$ & 33 (34.) & $97(100.0)$ & & \\
\hline Stage 2 & $42(61.8)$ & $26(38.3)$ & $68(100.0)$ & & \\
\hline Stage 3 & $35(55.6)$ & $28(44.4)$ & $63(100.0)$ & & \\
\hline Stage 4 & $13(59.1)$ & $9(40.9)$ & $22(100.0)$ & & \\
\hline Baseline & & & & & \\
\hline (copies/ml) & & & & $\Phi$ & 0.751 \\
\hline$<10000$ & $22(73.3)$ & 8 (26.7) & $30(100.0)$ & & \\
\hline 10,000 to 99,999 & $13(60.0)$ & $9(40.0)$ & $22(100.0)$ & & \\
\hline $100,000 \quad$ to & & & & & \\
\hline 499,999 & 8 (66.7) & $4(33.3)$ & $12(100.0)$ & & \\
\hline
\end{tabular}




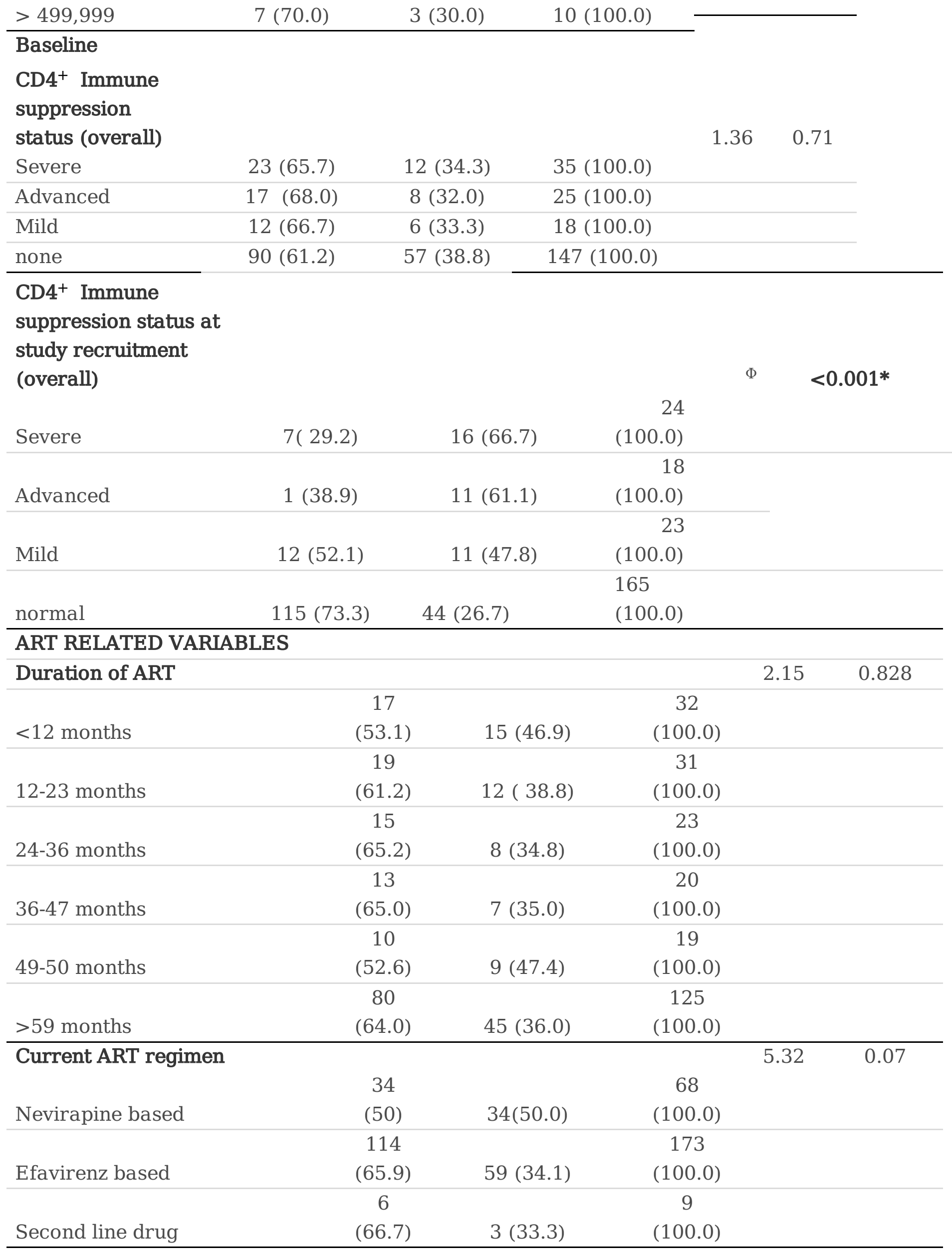


Adherence (Pill count

percentage rate)

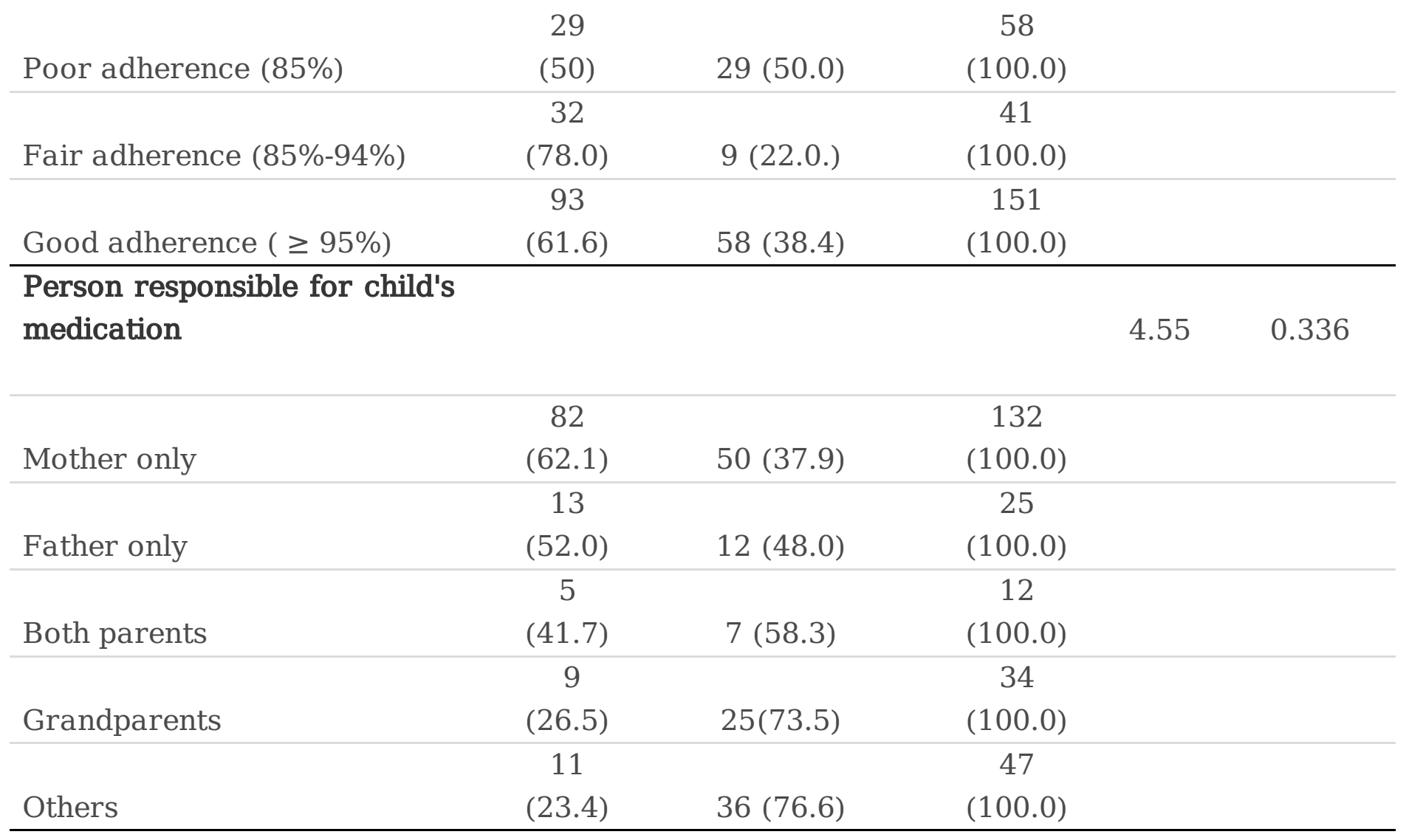

$\chi^{2}:$ Pearson's chi-square

$\%$ : row percentage

$*: \mathrm{p}<0.05$.

\section{Supplementary Files}

This is a list of supplementary files associated with this preprint. Click to download.

- equation.docx 